\author{
Andrzej SZELMANOWSKI ${ }^{1}$ \\ Sławomir MICHALAK ${ }^{2}$ \\ Andrzej PAZUR ${ }^{3}$
}

\title{
NAHELMOWY SYSTEM CELOWNICZY NSC-1 ORION DLA POLSKICH ŚMIGŁOWCÓW WOJSKOWYCH
}

\begin{abstract}
$\mathrm{W}$ pracy przedstawiono występujący $\mathrm{w}$ formie demonstratora technologii nahełmowy system celowniczy NSC-1 Orion, który został opracowany i zbudowany w ramach projektu badawczego na rzecz obronności i bezpieczeństwa państwa pt. „System nahełmowego sterowania uzbrojeniem śmigłowca W-3PL Głuszec”. System ten jest przeznaczony do nahełmowego sterowania położeniem stanowiska ruchomego z karabinem 12,7 WKM-B oraz innych elementów uzbrojenia śmigłowca. Umożliwia nahełmowe wyświetlanie parametrów pilotażowych zarówno w dzień, jak i w nocy. Projekt obejmujący budowę systemu NSC-1 Orion, jako głównego elementu systemu nahełmowego sterowania uzbrojeniem, został zrealizowany przez polskie konsorcjum naukowo-przemysłowe reprezentowane przez Instytut Techniczny Wojsk Lotniczych (Warszawa) jako lidera projektu. Osiągnięty poziom światowy oraz zastosowane nowatorskie technologie w tym rozwiązaniu zyskały uznanie na XX Międzynarodowym Salonie Przemysłu Obronnego w Kielcach, gdzie 6 września 2012 r. nahełmowy system celowniczy NSC-1 Orion uzyskał prestiżowe wyróżnienie DEFENDER.
\end{abstract}

Słowa kluczowe: system celowniczy, śmigłowiec, sterowanie

\section{Wprowadzenie}

Nahełmowe systemy zobrazowania i wskazywania celu (tzw. zintegrowane celowniki nahełmowe) stają się obecnie [1-3] podstawowym wyposażeniem nowoczesnych wielozadaniowych samolotów i śmigłowców bojowych. Stanowią one także istotny element przetargowy programów modernizacji starszych

${ }^{1}$ Andrzej Szelmanowski, Instytut Techniczny Wojsk Lotniczych, ul. Księcia Bolesława 6, 01-494 Warszawa, e-mail: andrzej.szelmanowski@itwl.pl

2 Autor do korespondencji/corresponding author: Sławomir Michalak, Instytut Techniczny Wojsk Lotniczych, ul. Księcia Bolesława 6, 01-494 Warszawa, tel.: (22) 6851043, e-mail: slawomir.michalak@itwl.pl

3 Andrzej Pazur, Instytut Techniczny Wojsk Lotniczych, ul. Księcia Bolesława 6, 01-494 Warszawa, e-mail: andrzej.pazur@itwl.pl 
technologicznie statków powietrznych. Głównym celem ich zastosowania jest zwiększenie tzw. świadomości sytuacyjnej pilota i bezpieczeństwa lotu, a także efektywności i skuteczności użycia uzbrojenia pokładowego oraz zdolności przetrwania załóg na współczesnym polu walki [4]. Nahełmowe systemy prezentacji danych w wersji klasycznej wykorzystują dzienne wyświetlacze okularowe i gogle noktowizyjne (rys. 1.), stanowiące standardowe wyposażenie m.in. wojskowych śmigłowców bojowych AH-1 Cobra i AH-64 Apache [5]. Umożliwiają one nie tylko bezpośrednie (tj. wyświetlane przed oczami pilota) informowanie o parametrach pilotażowo-nawigacyjnych (co jest bardzo ważne podczas lotów manewrowych), ale także podają komendy dyrektywne (nakazujące czynności niezbędne do wykonania zadania) lub ostrzeżenia o sytuacjach awaryjnych lub niesprawnościach (otrzymywane z układów kontroli stanu technicznego systemów pokładowych). Nahełmowe systemy prezentacji danych są wykorzystywane także do sterowania uzbrojeniem ruchomym statku powietrznego (np. w zakresie nahełmowego wskazywania celu dla działka lub rakiety kierowanej) oraz w systemach poszukiwawczo-ratowniczych (do sterowania położeniem kątowym głowicy obserwacyjno-celowniczej lub reflektora podwieszanego).

a)

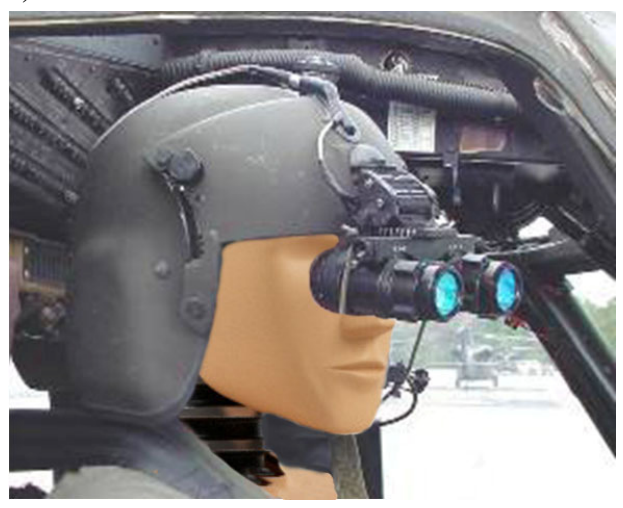

b)

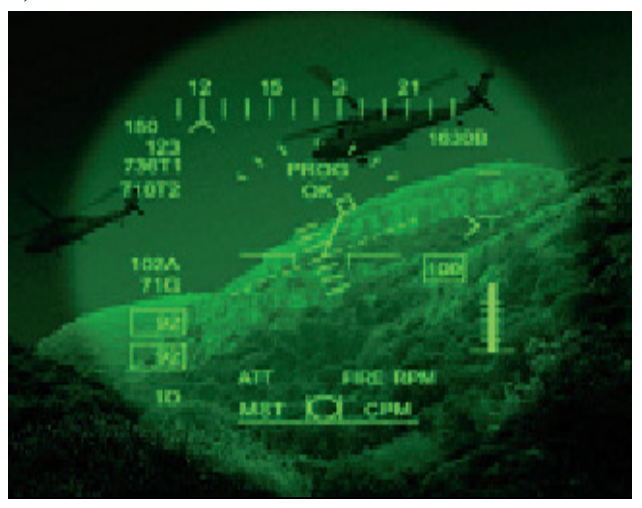

Rys. 1. Nahełmowy system celowniczy ANVIS dla śmigłowca AH-1 Cobra (a) oraz zobrazowanie okularowe w noktowizji (b)

Fig. 1. The helmet-mounted ANVIS sight system for AH-1 Cobra helicopter (a) and noctovision view in the eyepiece (b)

Prace rozwojowe systemów nahełmowej prezentacji danych i sterowania uzbrojeniem pokładowym to konstrukcje hełmów przystosowanych do działania w cyberprzestrzeni, np. system nahełmowy HMDS firmy VSI dla samolotu F-35 [3]. W Polsce podobny projekt, finansowany przez Ministerstwo Nauki i Szkolnictwa Wyższego oraz Narodowe Centrum Badań i Rozwoju, obejmował budowę systemu NSC-1 Orion jako głównego elementu systemu nahełmowego sterowania uzbrojeniem śmigłowca W-3PL Głuszec. Projekt ten został zrealizowa- 
ny przez polskie konsorcjum naukowo-przemysłowe w składzie: Instytut Techniczny Wojsk Lotniczych (Warszawa) jako lider projektu, Wytwórnia Sprzętu Komunikacyjnego „PZL-Świdnik” S.A. (Świdnik), Zakłady Mechaniczne „Tarnów" S.A. (Tarnów), FAS Mariusz Ficoń (Bielsko-Biała) oraz Przemysłowe Centrum Optyki/Bumar Żołnierz S.A. (Warszawa). Osiągnięty poziom światowy oraz zastosowane nowatorskie technologie w tym rozwiązaniu zyskały uznanie na XX Międzynarodowym Salonie Przemysłu Obronnego w Kielcach, gdzie 6 września 2012 r. nahełmowy system celowniczy NSC-1 Orion uzyskał prestiżowe wyróżnienie DEFENDER.

\section{Nahelmowy system celowniczy NSC-1 Orion}

Wychodząc naprzeciw potrzebom i standardom światowym, w Zakładzie Awioniki ITWL (we współpracy z firmą PCO i FAS w ramach konsorcjum naukowo-przemysłowego) opracowano i zbudowano [6] nahełmowy system celowniczy NSC-1 Orion (rys. 2.). Za pomocą zbudowanego nahełmowego systemu celowniczego NSC-1 Orion można sterować położeniem kątowym stanowiska ruchomego z karabinem 12,7 WKM-B (w wersji zbudowanej w ramach demonstratora technologii) oraz innych elementów systemu uzbrojenia pokładowego, m.in. ruchomej głowicy obserwacyjno-celowniczej Toplite, a także koordynatorów kierowanych pocisków rakietowych (w wersji rozwojowej). W celu zapewnienia działania system ten jest sprzężony z komputerem misji KM-1 (zabudowanym na śmigłowcu W-3PL Głuszec) oraz wymaga nahełmowego układu określania położenia kątowego hełmu i nahełmowego układu zobrazowania danych procesu celowania (w tym tzw. krzyża celowniczego umożliwiającego powstanie osi celowania dla oka pilota).

a)

b)
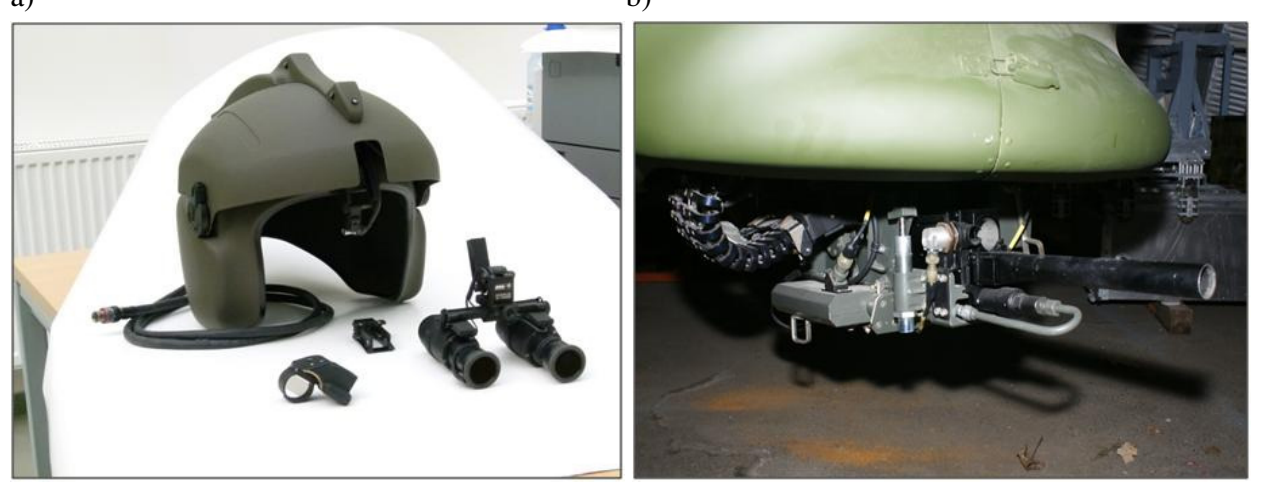

Rys. 2. Elementy nahełmowego systemu celowniczego NSC-1 Orion (a) i stanowisko ruchome z karabinem WKM-B (b) dla śmigłowca W-3PL Głuszec

Fig. 2. Elements of the helmet-mounted NSC-1 Orion sight system (a) and the mobile stand with WKM-B fifle (b) for W-3PL Gluszec helicopter 
Budowa nahełmowego systemu celowniczego w postaci systemu NSC-1 Orion, ze względu na jego specyfikę i rolę na wojskowym statku powietrznym $\mathrm{w}$ realizowaniu zadań [7], była związana $\mathrm{z}$ wieloma poważnymi problemami badawczymi. Obejmowały one zarówno zakres prac teoretycznych (m.in. opracowanie koncepcji działania systemu i wykorzystywanej zasady działania), jak i badań funkcjonalnych zbudowanego układu w wersji demonstratora technologii [8]. Wśród nich występowały problemy związane z:

- połączeniem budowanego systemu ze zintegrowanym systemem awionicznym śmigłowca W-3PL Głuszec (wymaganym dla zapewnienia dostarczania danych nawigacyjno-celowniczych do systemu oraz zarządzania systemem nahełmowym),

- wyświetlaniem nahełmowym danych (sposobem zobrazowania danych celowniczych na nahełmowym wyświetlaczu przeziernym),

- miniaturyzacją gabarytów i masy wyświetlacza nahełmowego i gogli noktowizyjnych (zapewnieniem jak najmniejszego obciążenia kręgosłupa szyjnego pilota),

- zapewnieniem płynności obracania i dokładności pozycjonowania ruchomego stanowiska strzeleckiego (oraz pozostałego kierowanego nahełmowo uzbrojenia pokładowego śmigłowca W-3PL Głuszec).

Głównym zagadnieniem badawczym było określenie możliwości i ograniczeń metod funkcjonowania nahełmowych systemów celowniczych (stosowanych na wybranych wojskowych statkach powietrznych lub nowo opracowanych), analizowanych w realizowanym projekcie budowy systemu NSC-1 Orion [7]. Celem przeprowadzonych prac była ocena tych metod (przedstawionych w ich realizacjach technicznych wykonanych w ITWL) pod kątem dokładności wyznaczania położenia kątowego hełmu pilota i wybór najbardziej korzystnej w stosunku do posiadanych w kraju możliwości technologicznych [8]. W wyniku przeprowadzonych analiz opracowano projekt koncepcyjny systemu nahełmowego sterowania uzbrojeniem z nahełmowym systemem celowniczym NSC-1 Orion. Schemat blokowy zbudowanego nahełmowego systemu sterowania uzbrojeniem śmigłowca W-3PL Głuszec przedstawiono na rys. 3.

W odniesieniu do zastosowanej zasady działania nahełmowy system celowniczy NSC-1 Orion jest autorskim, opracowanym w ITWL rozwinięciem metody elektrooptycznej (korygowanej przez jej hybrydyzację z układem inercjalno-magnetycznym). Zostało ono zrealizowane $\mathrm{z}$ wykorzystaniem optoelektronicznych elementów wskazujących położenie hełmu pilota oraz algorytmów opartych na sztucznej sieci neuronowej do wyznaczania jego położenia kątowego. Jako układ działający w ramach systemu nahełmowego sterowania uzbrojeniem zbudowanego dla śmigłowca W-3PL Głuszec system NSC-1 Orion realizuje funkcje nahełmowego procesu celowania i sterowania pracą środków bojowych (stanowiskiem ruchomym z karabinem 12,7 mm WKM-B) oraz współpracuje z głowicą obserwacyjno-celowniczą Toplite. Nahełmowy system celowniczy NSC-1 Orion jako system wydzielony korzysta z informacji pochodzących 


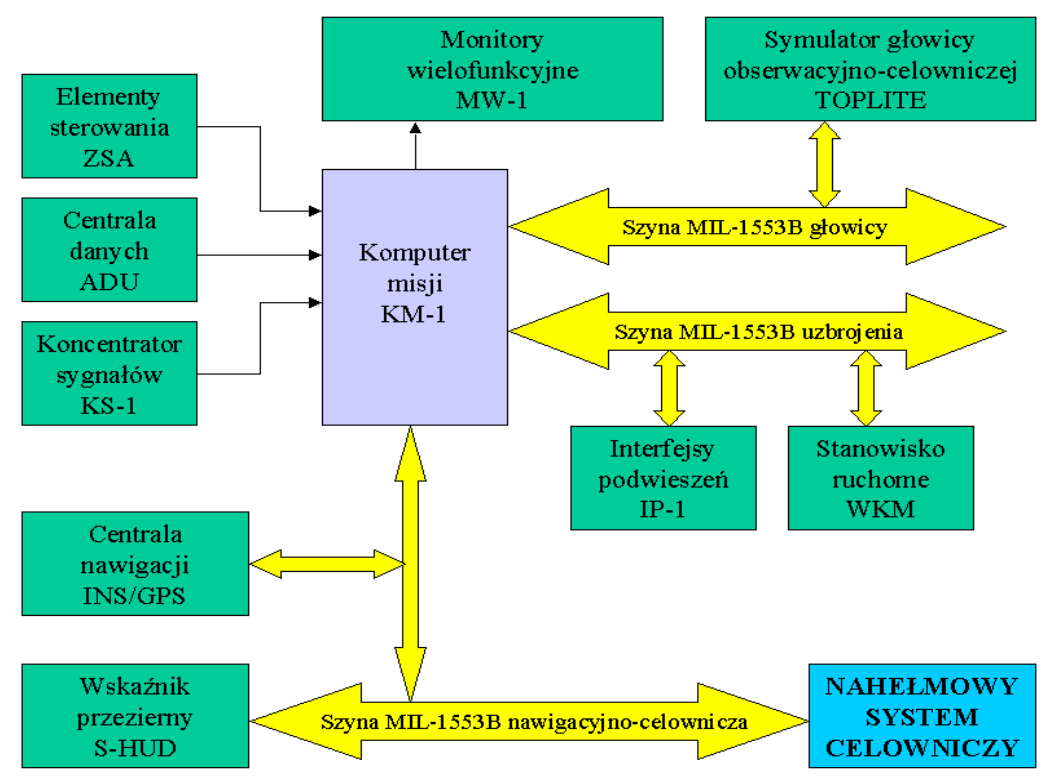

Rys. 3. Schemat połączenia nahełmowego systemu celowniczego jako nowego systemu z zintegrowanym systemem awionicznym śmigłowca W-3PL Głuszec

Fig. 3. Schematic of the connection of the helmet-mounted sight system as a new system integrated with aviation system of W-3PL Gluszec helicopter

od zintegrowanego systemu awionicznego (zabudowanego na pokładzie śmigłowca W-3PL Głuszec). W szczególności system ten współpracuje z dalmierzem laserowym głowicy obserwacyjno-celowniczej Toplite oraz pokładowym elektroenergetycznym układem zasilania. Współdziałanie systemu NSC-1 Orion z systemem awionicznym i innymi układami pomiarowymi na śmigłowcu jest realizowane za pomocą interfejsów: MIL-1553B, ARINC-429, RS-485, ETHERNET 10/100 oraz USB. Elementem integrującym system nahełmowy NSC-1 Orion jest komputer graficzny KG-1HC (rys. 4.) współpracujący z komputerem misji KM-1, stanowiącym główny element zarządzający pracą zintegrowanego systemu awionicznego śmigłowca W-3PL Głuszec.

Podstawą montażową demonstratora technologii jest makieta kabiny śmigłowca W-3PL Głuszec (wykonana przez WSK „PZL-Świdnik”), na której zostały zabudowane wybrane elementy zintegrowanego systemu awionicznego, niezbędne do uruchomienia systemu nahełmowego i sprawdzenia jego współdziałania ze zintegrowanym systemem awionicznym (opracowanym przez ITWL), oraz adaptowane na potrzeby projektu stanowisko ruchome $\mathrm{z}$ karabinem WKM-B (wykonane przez ZM „Tarnów”). Nahełmowy system celowniczy NSC-1 Orion spełnia w systemie nahełmowego sterowania uzbrojeniem śmigłowca W-3PL Głuszec funkcje: wizualizacji symboli celowniczych na naheł- 
a)

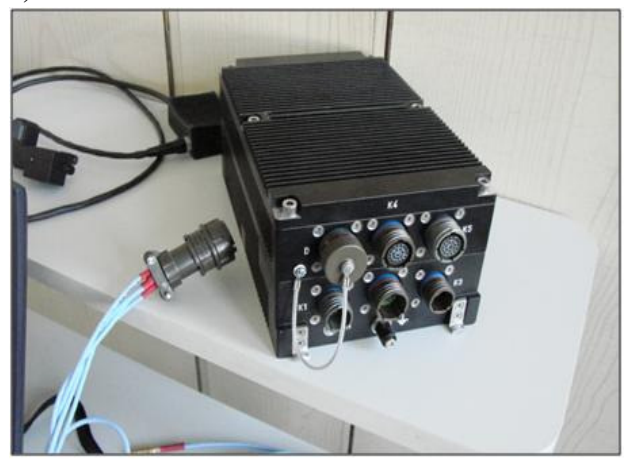

b)

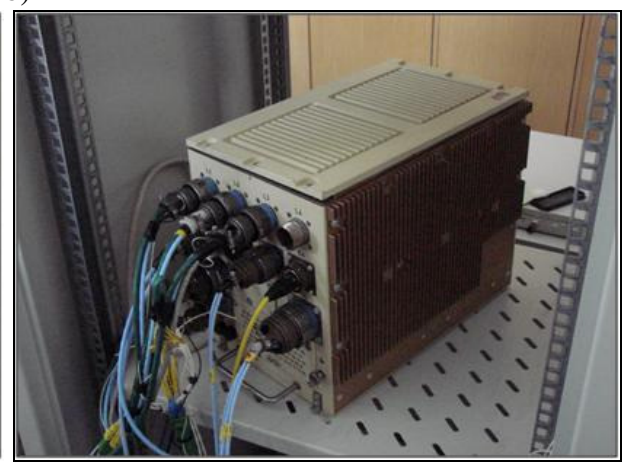

Rys. 4. Komputer graficzny KG-1HC nahełmowego systemu celowniczego NSC-1 Orion (a) i komputer misji KM-1 (b) dla śmigłowca W-3PL Głuszec

Fig. 4. KG-1HC graphic computer of the helmet-mounted NSC-1 Orion sight system (a) and the computer of KM-1 mission (b) for W-3PL Gluszec helicopter

mowym wyświetlaczu przeziernym (uwzględniającej aktualnie używane uzbrojenie oraz jego dane balistyczne), wycelowania wybranego systemu uzbrojenia ruchomego na śmigłowcu do celu zewnętrznego (przez operatora systemu), pomiaru kątów azymutu i elewacji hełmu pilota względem kabiny śmigłowca i przesłania ich w postaci cyfrowej do aplikacji wypracowującej dane balistyczno-celownicze w komputerze misji. W sterowaniu systemem uzbrojenia zbudowany demonstrator technologii systemu nahełmowego sterowania uzbrojeniem śmigłowca W-3PL Głuszec obejmuje adaptowane ruchome stanowisko strzeleckie (z 12,7 mm karabinem WKM-B) oraz stanowisko do symulacji wybranych parametrów funkcjonalnych głowicy obserwacyjno-celowniczej Toplite (symulator SGT-1 zbudowany w ITWL).

\section{Podstawowe funkcje i dokładność pozycjonowania hełmu}

W obszarze rozwiązań technologicznych przedstawiony system NSC-1 Orion jest oparty na innowacyjnych rozwiązaniach niespotykanych w skali światowej [6]. Zastosowane rozwiązania konstrukcyjne i technologiczne w zbudowanym systemie nahełmowego sterowania uzbrojeniem śmigłowca W-3PL Głuszec są na najwyższym poziomie technologicznym. Przełomowym rozwiązaniem $\mathrm{w}$ realizowanym projekcie jest zastosowanie technologii sztucznych sieci neuronowych do określania położenia kątowego hełmu pilota (opracowanej w ITWL) oraz zintegrowanego wyświetlacza dzienno-nocnego WDN-1 (zbudowanego w PCO), wykorzystywanego do celów nahełmowego zobrazowania informacji pilotażowo-nawigacyjnej i celowniczej z implementacją techniki noktowizyjnej (zminiaturyzowane gogle noktowizyjne PNL-3M zbudowane w PCO).

Działanie systemu nahełmowego NSC-1 Orion polega na takim sterowaniu uzbrojeniem śmigłowca, w którym ruch głowy pilota w zakresie azymutu i ele- 
wacji powoduje odpowiedni ruch osi celowania ruchomego stanowiska strzeleckiego z karabinem 12,7 mm WKM-B. Umożliwia to prowadzenie ognia bez odrywania rąk od elementów sterowania i nahełmowego wskazywania celu oraz szybkie przełączanie systemu na sygnały głowicy obserwacyjno-celowniczej wykorzystywane do strzelania precyzyjnego. Wstępne badania dokładności kreślania kątów położenia przestrzennego hełmu pilota dla nahełmowego systemu celowniczego NSC-1 Orion były wykonywane na stanowisku pomiarowym, zbudowanym w ITWL do uczenia sieci neuronowej wykorzystywanej w metodzie elektrooptycznej i hybrydowej [6]. Stanowisko takie dla badanej aplikacji z siecią neuronową zapewnia: zautomatyzowane zadawanie i pomiar kątów azymutu i elewacji osi celowania, zautomatyzowany pomiar położenia przestrzennego hełmu poprzez wyznaczenie kątów azymutu i elewacji osi wizowania hełmu za pomocą systemu pomiaru, przesłanie tych kątów w postaci cyfrowej do aplikacji pomiarowej w celu archiwizacji i dalszej analizy, określanie dokładności wyznaczania położenia kątowego.

Stanowisko w wersji uproszczonej (z modelowaniem położenia hełmu na obrotnicy PAN/TILT) pozwala na zadawanie położenia przestrzennego hełmu poprzez zmianę jedynie jego kątów azymutu i elewacji względem dwóch prostopadłych osi obrotu, bez uwzględniania przemieszczeń bocznych. Wykonane badania dla metody hybrydowej wykazały, że dokładność tak wyznaczanych kątów azymutu i elewacji hełmu (dla azymutu do $\pm 80^{\circ}$ i elewacji do $\pm 12^{\circ}$ ) jest rzędu $\pm 0,5^{\circ}$ (dla azymutu) oraz $\pm 0,2^{\circ}$ (dla elewacji). Końcowe badania dokładności określania kątów były wykonywane na stanowisku w wersji pełnej, zabudowanym w kabinie śmigłowca W-3PL Głuszec. Stanowisko w wersji pełnej (z hełmem umieszczonym na głowie operatora systemu) pozwala na rzeczywiste zadawanie położenia kątowego hełmu z uwzględnieniem ruchów bocznych głowy i tułowia pilota występujących w procesie celowania. Wykonane badania dla metody hybrydowej wykazały, że dokładność tak wyznaczanych kątów azymutu i elewacji hełmu (dla azymutu do $\pm 80^{\circ}$, dla elewacji do $\pm 12^{\circ}$ ) jest rzędu $\pm 0,6^{\circ}$ (dla azymutu) oraz $\pm 0,3^{\circ}$ (dla elewacji).

Na podstawie wyników badań wykonanych w ITWL stwierdzono, że obecnie najbardziej dogodną do zastosowania w nahełmowym systemie celowniczym NSC-1 Orion jest metoda hybrydowa. Stanowi ona jeden ze sposobów zwiększenia dokładności wyznaczania położenia kątowego hełmu przez połączenie kilku metod składowych (elektrooptycznej i inercjalnej). System ten może być optymalizowany w zakresie liczby i rodzaju sygnałów oraz sposobu ich przetwarzania (np. używając filtru Kalmana). Niebagatelną zaletą systemu NSC-1 Orion jest zbudowanie go na podstawie zintegrowanego systemu awionicznego śmigłowca W-3PL Głuszec, wykorzystującego cyfrowe szyny danych MIL-1553B (w zarządzaniu pracą systemu nahełmowego) i MIL-1760 (w sterowaniu pracą systemu uzbrojenia). Umożliwia to zabudowanie go na innych, nowych lub modernizowanych śmigłowcach bojowych ze zintegrowanym systemem awionicz- 
nym [8]. Zbudowany nahełmowy system celowniczy NSC-1 Orion jako demonstrator technologii wspomaga proces testowania nowych metod (oraz urządzeń do ich realizacji technicznej) i może stanowić podstawę do dalszego ich rozwoju w ramach przemysłu krajowego.

\section{Podsumowanie}

Nahełmowy system celowniczy NSC-1 Orion został zbudowany do nahełmowego sterowania ruchomym stanowiskiem strzeleckim z karabinem 12,7 mm WKM-B oraz współdziałania z głowicą obserwacyjno-celowniczą Toplite (zabudowanymi na pokładzie śmigłowca W-3PL Głuszec). System ten jest elektronicznie sprzężony ze zintegrowanym systemem awionicznym śmigłowca W-3PL Głuszec. Dzięki temu jest on przygotowany do pracy w tzw. systemie sieciocentrycznym, umożliwiającym realizację zaawansowanego szkolenia lotniczego personelu latającego i spełniającym warunki użycia go do realizacji misji bojowych na współczesnym polu walki w każdych warunkach dobowych (dzienno-nocnych). W wersji rozwojowej system ten może sterować położeniem kątowym głowicy obserwacyjno-celowniczej (z możliwością nahełmowego zobrazowania informacji z niej otrzymywanej) oraz może być wykorzystany do nahełmowego wskazywania celu dla pocisków kierowanych (typu „powietrzepowietrze" i ,powietrze-ziemia").

Nowoczesność systemu NSC-1 Orion polega na tym, że jest zbudowany w architekturze otwartej, przeznaczonej do zabudowy na śmigłowcach posiadających odpowiedni poziom technologiczności (m.in. W-3PL Głuszec). Do realizacji funkcji nahełmowego sterowania uzbrojeniem śmigłowca system ten określa w tych samych układach współrzędnych położenie hełmu, głowicy i stanowiska ruchomego. Niezbędne dane dla nahełmowego systemu celowniczego NSC-1 Orion są pobierane z części nawigacyjnej zintegrowanego systemu awionicznego zabudowanego na śmigłowcu W-3PL Głuszec. Aby zapewnić ergonomiczność i skrócenie procesu przygotowania do użycia uzbrojenia pokładowego, parametry pilotażowo-nawigacyjne oraz dane dla procesu celowania są zobrazowane na zintegrowanym wyświetlaczu dzienno-nocnym WDN-1, zamontowanym na hełmie pilota. System współpracuje z najnowszymi (opracowanymi w PCO) zminiaturyzowanymi goglami noktowizyjnymi PNL-3M, zmniejszającymi obciążenie kręgosłupa szyjnego pilota.

Zbudowany system nahełmowego sterowania uzbrojeniem jest wykonany z uwzględnieniem zadań stawianych przed współczesnymi śmigłowcami bojowymi. Nahełmowa prezentacja danych pilotażowo-nawigacyjnych zastosowana w systemie NSC-1 Orion bezpośrednio przyczynia się do zwiększenia bezpieczeństwa lotu i walorów bojowych śmigłowca W-3PL Głuszec. System ten otrzymał Nagrodę DEFENDER na XX Międzynarodowym Salonie Przemysłu Obronnego MSPO'2012 w Kielcach. 


\title{
Literatura
}

[1] Materiały reklamowe firmy BOEING: Joint Helmet-Mounted Cueing System, 2008.

[2] Materiały reklamowe firmy LOCKHEED MARTIN: A new technology Joint Helmet Mounted Cueing System for F-16 aircraft, 2009.

[3] Materiały reklamowe firmy VISION SYSTEMS INTERNATIONAL: World leader in tactical aircraft helmet mounted display systems, 2012.

[4] Girolamo H., Rash C., Gilroy T.: Advanced information display for the $21^{\text {st }}$ century warrior. USAART, 1997.

[5] Rash C., Russo M., Letowski T., Schmeisser E.: Helmet mounted displays: Sensation, perception and cognition issues. USAARL, 2009.

[6] Zubko W., Milewski W., Pietnoczko B.: System nahełmowego sterowania uzbrojeniem śmigłowca W-3PL Głuszec. Demonstrator technologii. Opis techniczny i instrukcja użytkowania. BT ITWL, Warszawa 2012.

[7] Szelmanowski A., Michalak S., Pazur A.: Wstępne założenia taktyczno-techniczne na nahełmowy system celowniczy (NSC) dla śmigłowców z zabudowanym systemem ZSA (np. W-3PL Głuszec). BT ITWL, Warszawa 2010.

[8] Zubko W., Milewski W., Pietnoczko B.: Badania systemu nahełmowego sterowania uzbrojeniem śmigłowca W-3PL Głuszec. Badania laboratoryjne. Badania konstrukcyjne, elektryczne i funkcjonalne. BT ITWL, Warszawa 2012.

\section{HELMET-MOUNTED SIGHT NSC-1 ORION SYSTEM FOR POLISH MILITARY HELICOPTERS}

\begin{abstract}
A bstract
In the paper the demonstration of the helmet-mounted Sight System NSC-1 Orion developed and built within a framework of project for national defense and security named "A Helmetmounted system to control the armament system of W-3PL Gluszec helicopter" is presented. The NSC-1 Orion system is dedicated to helmet-mounted control of the homing position of turret gun 12,7 WKM-B and other armament elements of the helicopter. Furthermore, it allows to helmetmounted display the pilotage parameters during the day and night flights. The project has focused on the designing of the NSC-1 Orion system as the main element of the helmet-mounted system of the armament control and it has been realized by the Polish scientific-industrial consortium represented by the Air Force Institute of Technology (Warsaw) as the project leader. The achieved world level of the NSC-1 Orion system and innovative technologies used in this solution receive recognition at the 20th International Defence Industry Exhibition in Kielce, where on 6th September, 2012, the NSC-1 Orion sight helmet-mounted system has received a prestigious award DEFENDER.
\end{abstract}

Keywords: sight system, helicopter, control

DOI:10.7862/rm.2013.30

Otrzymano/received: 15.09 .2013

Zaakceptowano/accepted: 22.10 .2013 